\title{
Oxidative Sulfur Removal from Complex Copper Concentrate
}

\author{
Byung-Su Kim, Hoo-In Lee*, Jin-Tae Park, Jeong-Soo Sohn and Jae-Chun Lee \\ Minerals \& Materials Processing Division, Korea Institute of Geoscience \& Mineral Resources, Daejeon, Korea
}

It is very important to remove sulfur from complex copper concentrates for smelting them by a carbon reduction process since copper concentrates are progressively becoming complex and low grade. The carbon reduction process largely consists of the oxidation process of complex copper concentrate and smelting process of the oxidized concentrate. In the present work, the kinetics study has been performed on a complex copper concentrate to understand the oxidation process over a temperature range of 998 to $1073 \mathrm{~K}$ and an oxygen partial pressure range of 15.20 to $50.66 \mathrm{kPa}$ using a thermogravimetric method. It was found that the oxidation rate was very fast under the whole temperature range and almost $95 \%$ of sulfur contained in the concentrate was removed after $15 \mathrm{~min}$ at $1073 \mathrm{~K}$ under an oxygen partial pressure of $21.28 \mathrm{kPa}$. Sulfur removal ratio as a function of time has been analyzed by using a shrinking-core model and the effect of oxygen partial pressure has been elucidated. [doi:10.2320/matertrans.MER2008081]

(Received March 4, 2008; Accepted May 13, 2008; Published July 25, 2008)

Keywords: complex copper concentrate, oxidation process, copper, shrinking-core model

\section{Introduction}

It has been seriously considered in the copper smelting industry that copper concentrates involving copper as well as small amounts of precious metals such as gold, silver and so on are becoming more and more complex and low grade since the sources of clean deposits are progressively depleted. Thus, in the recent, a carbon reduction process for smelting valuable metals like copper and precious metals from such complex and low grade copper concentrates becomes to be worthy of consideration. ${ }^{1,2)}$ The carbon reduction process could treat the dead-roasted copper concentrates (produced from the removal of sulfur by oxidative roasting of complex copper concentrates) to produce blister copper without producing and converting matte. Thus, the process allows great flexibility with respect to the selection of copper ore types, and do not impose limits on the minimum quantities of contained base copper metal or sulfur.

A kinetic analysis for the oxidation reaction of complex copper concentrate under nonisothermal condition in air using thermogravimetic analysis (TGA) equipment was presented in the previous paper. ${ }^{3)}$ However, the effect of oxygen partial pressure on the reaction was not investigated in the previous study. It was also investigated in the previous study that large amount of sulfate compounds such as $\mathrm{ZnSO}_{4}, \mathrm{CuSO}_{4}$ and $\mathrm{PbSO}_{4}$ as intermediate compounds of the reaction are produced under nonisothermal condition in air. Therefore, in this paper, the rate of the oxidation reaction of complex copper concentrate under isothermal condition in order to minimize formation of the intermediate compounds was measured thermogravimetrically. Both the oxygen partial pressure and reaction temperature were varied, the reaction order and activation energy being determined.

\section{Experimental Work}

Experiments were carried out in a thermogravimetic analysis (TGA) apparatus described in the previous paper to measure the rate of oxidation reaction of complex copper

*Corresponding author, E-mail: hilee@kigam.re.kr
Table 1 Chemical composition of the natural complex copper concentrate incinerated at $873 \mathrm{~K}$ for $2 \mathrm{~h}$ under nitrogen atmosphere. (mass $\%$ )

\begin{tabular}{cccccccc}
\hline $\mathrm{Cu}$ & $\mathrm{Zn}$ & $\mathrm{Fe}$ & $\mathrm{Pb}$ & $\mathrm{Au}$ & $\mathrm{Ag}$ & $\mathrm{SiO}_{2}$ & $\mathrm{~S}$ \\
\hline 14.9 & 29.1 & 12.2 & 6.6 & $145 \mathrm{ppm}$ & $1045 \mathrm{ppm}$ & 11.5 & 23.8 \\
\hline
\end{tabular}

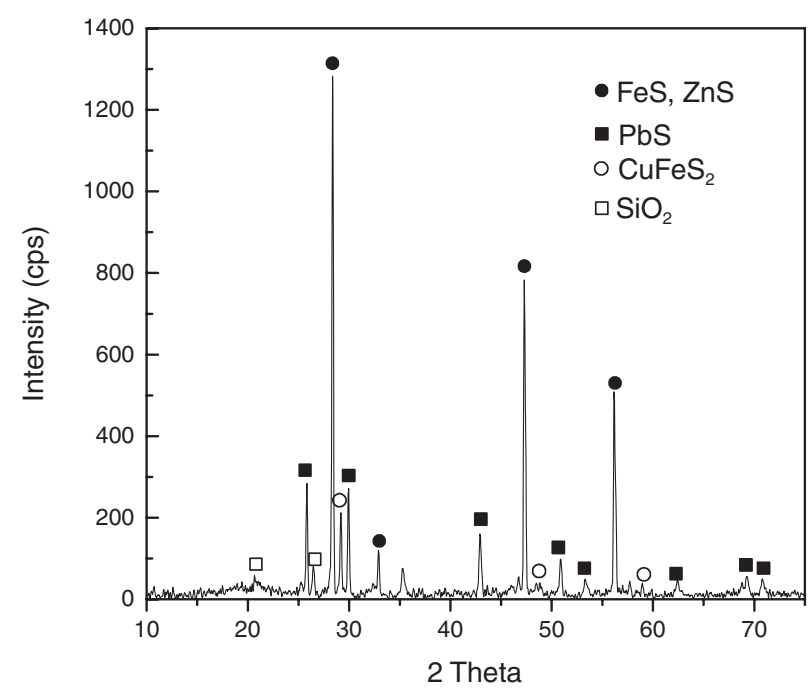

Fig. 1 XRD pattern of the complex copper concentrate incinerated at $873 \mathrm{~K}$ for $2 \mathrm{~h}$ under nitrogen atmosphere.

concentrate with oxygen-nitrogen gas mixtures. ${ }^{3)}$ A natural complex copper concentrate used in the study was obtained from Mankayan mine in Benguet, Philippine, which was grinded $-74 \mu \mathrm{m}$ by ball mill and incinerated to remove volatile materials at $873 \mathrm{~K}$ for 2 hours under nitrogen atmosphere. The sample mainly contains about $14.9 \% \mathrm{Cu}$, $29.1 \% \mathrm{Zn}, 11.5 \% \mathrm{SiO}_{2}, 12.2 \% \mathrm{Fe}$ and $23.8 \% \mathrm{~S}$. Table 1 shows chemical composition of the complex copper concentrate used in the study. Figure 1 presents the XRD pattern of the complex copper concentrate. The XRD analysis found metals like copper, zinc, lead, and iron in the complex copper concentrate are present as sulfides such as $\mathrm{CuFeS}_{2}, \mathrm{ZnS}$, $\mathrm{PbS}$, and $\mathrm{FeS}$, respectively. 
The morphological characterization of the samples was performed using a scanning electron microscope (JSM6380LV, JEOL Ltd, Tokyo, Japan) equipped with an energy dispersive X-ray spectrometer (Link Isis 3.0, Oxford Instrument plc, Oxon, U.K). The XRD patterns were obtained using a X-ray diffractometer (Rigaku D-max2500PC, Rigaku/MSC, Inc., TX, U.S.A) with $\mathrm{Cu} \mathrm{K \alpha}$ radiation $(\lambda=0.154 \mathrm{~nm})$ operated at $40 \mathrm{kV}$ and $30 \mathrm{~mA}$. Samples before and after the oxidation reaction were analyzed for $\mathrm{Fe}, \mathrm{Si}$, and $\mathrm{S}$ by wet chemistry and for $\mathrm{Cu}$, $\mathrm{Zn}$, and $\mathrm{Pb}$ by the inductively coupled plasma (ICP) method (JY-38 plus, Horiba Ltd, Kyoto, Japan).

\section{Results and Discussion}

\subsection{Behavior of the oxidation reaction}

Rate measurements for the oxidation reaction of natural complex copper concentrate powder were carried out at temperature ranges between 998 and $1073 \mathrm{~K}$ under oxygen partial pressures between 15.20 and $50.66 \mathrm{kPa}$. The experiments were continued until the solid sample showed no noticeable further mass change. A typical oxidation reaction pattern obtained at $1023 \mathrm{~K}$ under an oxygen partial pressure of $50.66 \mathrm{kPa}$ was shown in Fig. 2. The oxidative reaction patterns obtained under other conditions were similar except for the amount of weight increase at the initial period (about 4.5-5 min). Also, the weight decrease during about $2 \mathrm{~min}$ after inserting the reactant gas was shown due to exchanging the inserting gases into the reactor. As shown in Fig. 2, the weight increase occurred in the initial period of the oxidation reaction. During the period of weight increase, the sulfur removal ratio was approximately $5 \%$. In this period, the weight increase might be due to the formation of sulfate compounds such as $\mathrm{ZnSO}_{4}, \mathrm{CuSO}_{4}$, and $\mathrm{PbSO}_{4}$ prior to that of metal oxides such as $\mathrm{ZnO}, \mathrm{CuO}$, and $\mathrm{PbO}$, which was explained in the previous paper. ${ }^{3)}$ However, it was very difficult in the study to detect the XRD patterns of sulfate compounds such as $\mathrm{ZnSO}_{4}, \mathrm{CuSO}_{4}$, and $\mathrm{PbSO}_{4}$ at samples after the oxidation reaction for about $5 \mathrm{~min}$ at $1023 \mathrm{~K}$. This might be the reason that the amounts of the sulfate compounds produced at the initial period of the oxidation reaction are relatively small. Therefore, it was considered in the oxidation reaction of the natural complex copper concentrate under oxygen atmosphere that sulfate compounds

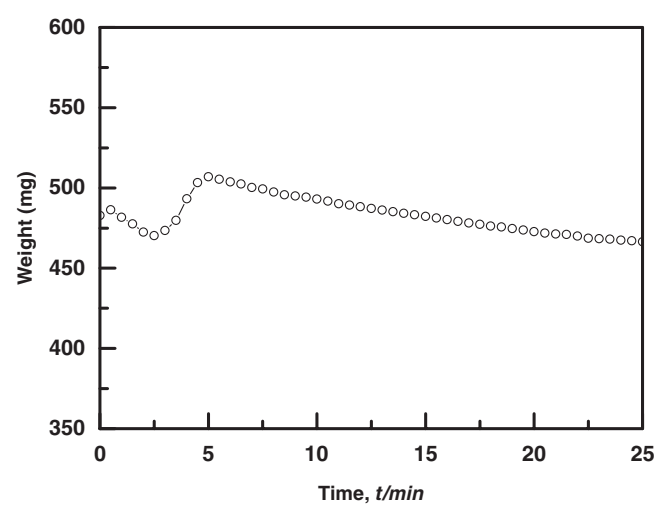

Fig. 2 A typical TGA curve of the oxidation reaction of complex copper concentrate at $1023 \mathrm{~K}$ under an oxygen partial pressure of $50.66 \mathrm{kPa}$.

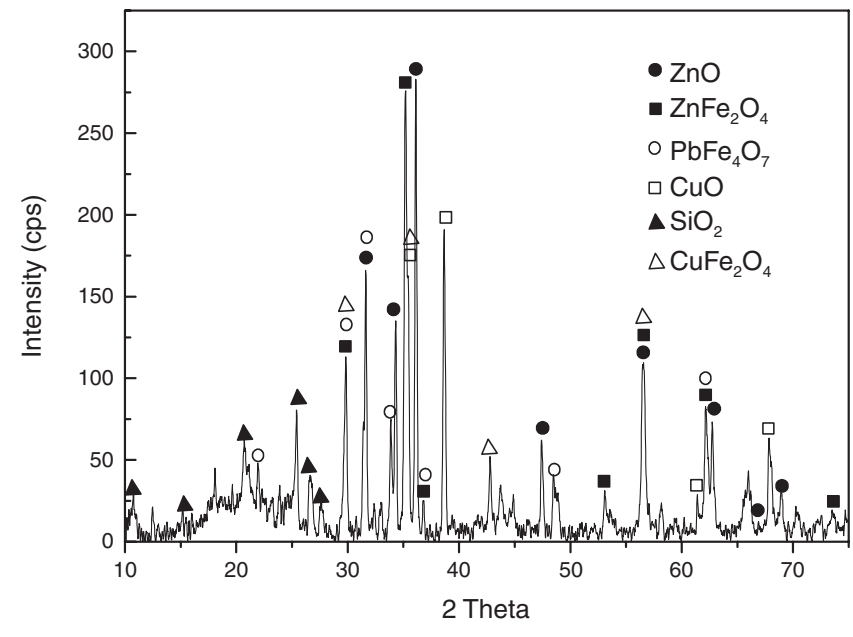

Fig. 3 XRD pattern of the product formed after the oxidation reaction at $1073 \mathrm{~K}$ under an oxygen partial pressure of $21.28 \mathrm{kPa}$.

like $\mathrm{ZnSO}_{4}, \mathrm{CuSO}_{4}$, and $\mathrm{PbSO}_{4}$ as intermediate compounds were mainly formed in the initial period of the oxidation reaction, and after the period the removal reaction of sulfur occurs mainly. Figure 3 shows the XRD pattern of a sample after the oxidation reaction at $1073 \mathrm{~K}$ under an oxygen partial pressure of $21.28 \mathrm{kPa}$. As shown in the figure, the XRD pattern of metal oxides was only detected at the sample.

Kinetic analysis of the thermal data obtained after the initial period of the oxidation reaction of natural complex copper concentrate were done in order to interpret the mechanism of the reaction and the dependency of oxygen partial pressure. In the present study, the removal ratio of sulfur from the complex copper concentrate at a particular time $\left(X_{\mathrm{t}}\right)$ during the oxidation reaction was defined as:

$$
X_{\mathrm{t}}=X_{\mathrm{f}} \frac{W_{\mathrm{I}}-W_{\mathrm{t}}}{W_{\mathrm{I}}}
$$

where $X_{\mathrm{f}}$ is the total removal ratio of sulfur at finishing the oxidation reaction, $W_{\mathrm{I}}$ is the initial weight $(\mathrm{mg})$ of solid sample, and $W_{\mathrm{t}}$ is the weight $(\mathrm{mg})$ of solid sample at a particular time. Here, the rates were measured by minimizing the effects of external mass transfer by using a sufficiently high flow rate $(1.0 \mathrm{~L} / \mathrm{min})$ of oxygen-nitrogen gas mixtures and small amount (450-550 mg) of natural complex copper concentrate, which was chosen through the preliminary experiments.

\subsection{Interpretation of the rate data}

The effect of reaction temperature on the oxidation reaction rate was determined by varying the reaction temperatures between 998 and $1073 \mathrm{~K}$ at a fixed oxygen partial pressure of $21.28 \mathrm{kPa}$, while all other experimental variables, such as sample mass and gas flow rate, were nearly identical for the measurement. The effect of reaction temperature on the oxidation reaction rate is presented in Fig. 4. These curves show that the removal ratio of sulfur increases with increasing the reaction temperature. It is also seen that almost $95 \%$ of sulfur was removed in 15 min at $1073 \mathrm{~K}$ under an oxygen partial pressure of $21.28 \mathrm{kPa}$. Figure 5 shows the effect of oxygen partial pressure on the oxidation reaction. The effect of oxygen partial pressure on the oxidation 


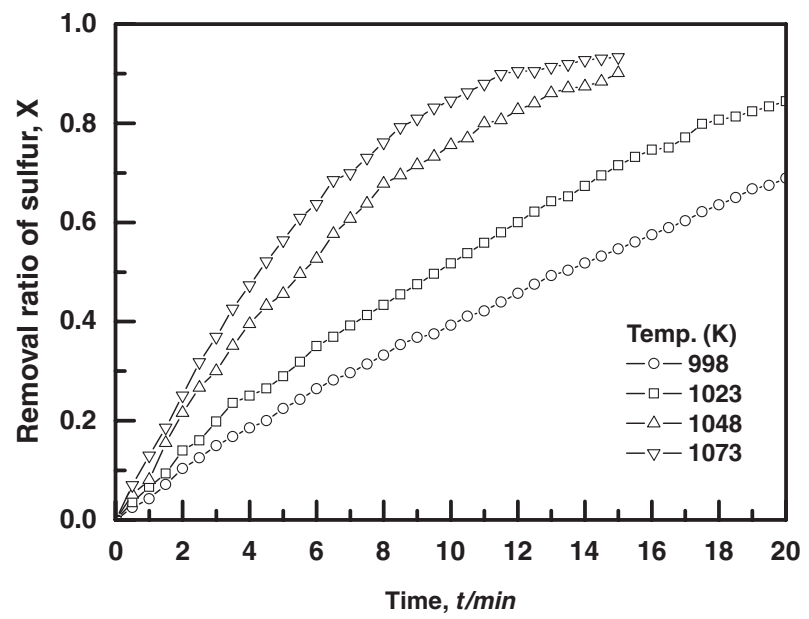

Fig. 4 Effect of reaction temperature on the oxidation reaction of complex copper concentrate at an oxygen partial pressure of $21.28 \mathrm{kPa}$.

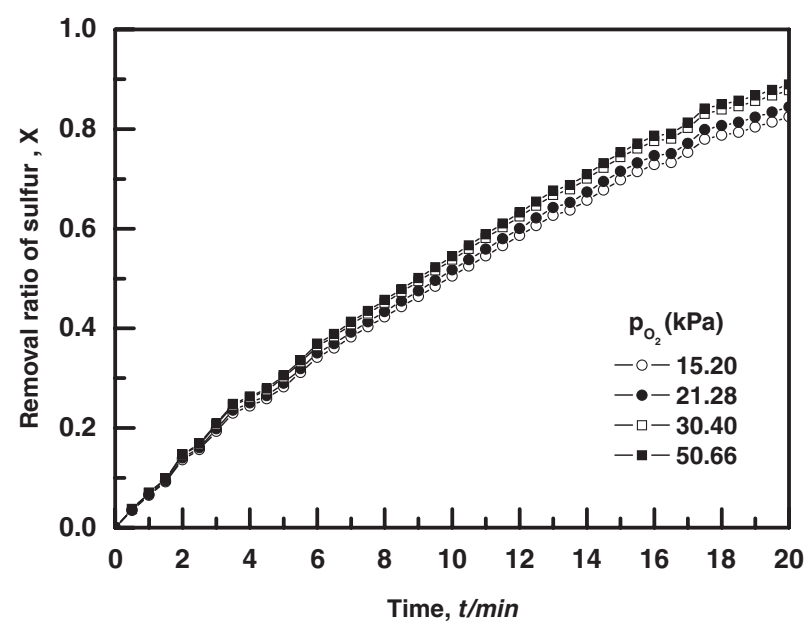

Fig. 5 Effect of oxygen partial pressure on the oxidation reaction of complex copper concentrate at $1023 \mathrm{~K}$.

reaction rate was measured by varying the oxygen partial pressure at a fixed reaction temperature of $1023 \mathrm{~K}$. This was done by varying the flow rates of air, nitrogen, and oxygen gases while maintaining the total flow rate at $1.0 \mathrm{~L} / \mathrm{min}$. As shown in the figure, under an oxygen partial pressure of $21.28 \mathrm{kPa}$, almost $85 \%$ of sulfur was removed in $20 \mathrm{~min}$.

In the present study, the removal ratio of sulfur until 0.90 was investigated for the kinetic analysis of the oxidation reaction. The interpretation of the rate data was performed using a number of different rate equations including the nucleation and growth model and pore-blocking model, from which shrinking-core model with chemical reaction control proved to yield the best results. On the other hand, in the study of the reaction of a natural enargite ore with oxygen, I. Mihajlovic et al. reported that the shrinking-core model was found to fit the reaction rate of sulfur removal. ${ }^{4)}$ The applicability of this rate expression can be expected from the fact that the formation of metal oxides like $\mathrm{ZnO}, \mathrm{CuO}$, $\mathrm{PbO}$, and $\mathrm{Fe}_{2} \mathrm{O}_{3}$ during the oxidation reaction begins at the outer particle surface.

In this rate expression, the removal ratio of sulfur is related to the reaction time by ${ }^{5,6}$ )

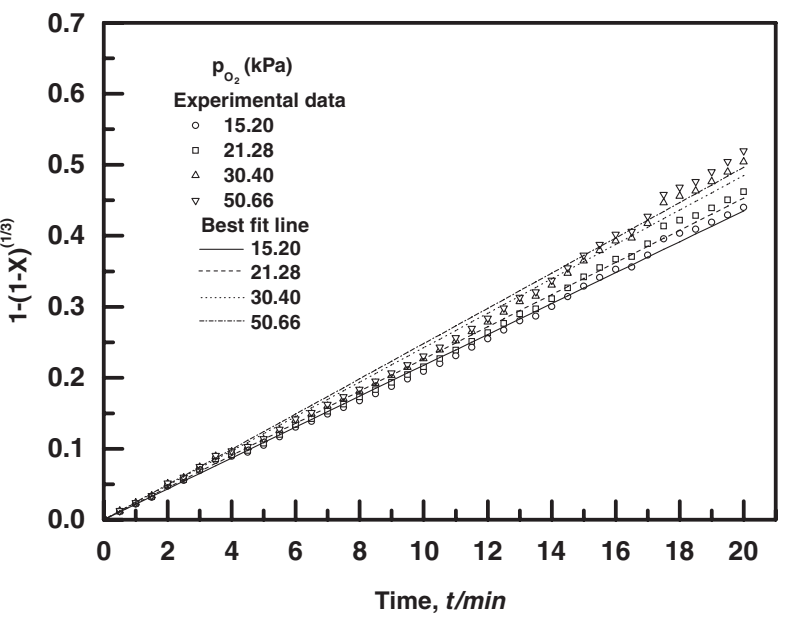

Fig. 6 Plot of the results in Fig. 5 according to eq. (2).

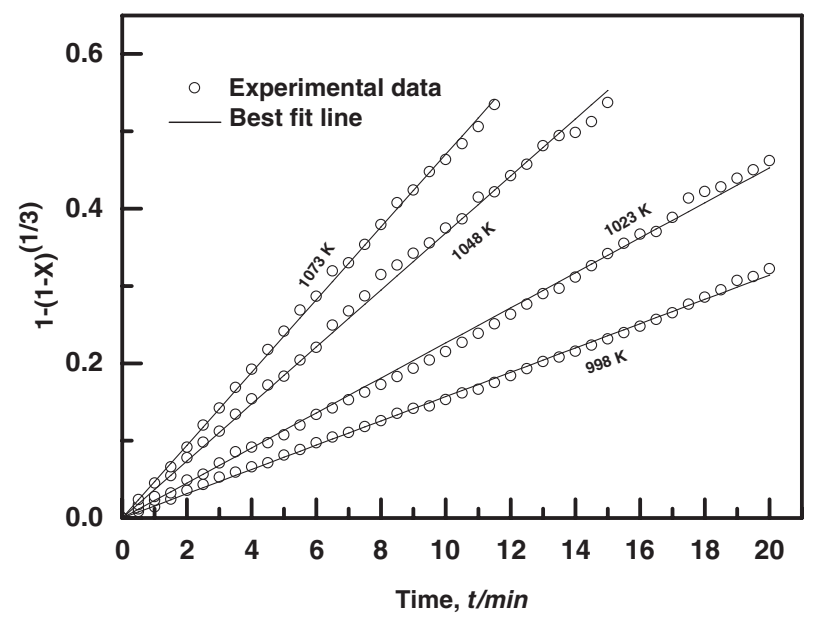

Fig. 7 Plot of the results in Fig. 4 according to eq. (2).

$$
1-(1-X)^{1 / 3}=k_{\mathrm{app}} t
$$

where $X$ is the removal ratio of sulfur, $t$ is the reaction time ( $\min )$, and $k_{\text {app }}$ is the apparent rate constant $\left(\min ^{-1}\right)$, which is given by

$$
k_{\text {app }}=b k f\left(p_{\mathrm{O}_{2}}\right)=k p_{\mathrm{O}_{2}}{ }^{n}\left(\min ^{-1}\right)
$$

Here, $b$ is the stoichiometry constant (according to the formulation of $\mathrm{Sohn}^{7)}$ ) for the oxidation reaction of complex copper concentrate with oxygen. In the system, it was assumed that $b$ equals unit because the oxidation reaction contains many reactions like copper, zinc, and lead oxidation reactions, not only one reaction. Also, $k$ is the intrinsic rate constant $\left(\mathrm{min}^{-1} \cdot \mathrm{kPa}^{-\mathrm{n}}\right), p_{\mathrm{O}_{2}}$ is the oxygen partial pressure ( $\mathrm{kPa}), f$ designates the partial pressure dependence of the rate, and $n$ is the reaction order for the oxygen partial pressure. It is apparent from eq. (2) that a plot of $1-$ $(1-X)^{1 / 3}$ against $t$ should be linear with $k_{\text {app }}$ as the slope.

The validity of the shrinking-core model rate expression for the oxidation reaction of complex copper concentrate with oxygen was verified by first plotting the curves of Figs. 4 and 5 according to eq. (2), as shown in Figs. 6 and 7. Examination of these figures reveals that the rate data follow well eq. (2). In these Figs. 6 and 7, the values of the slopes were calculated by regression analysis. 


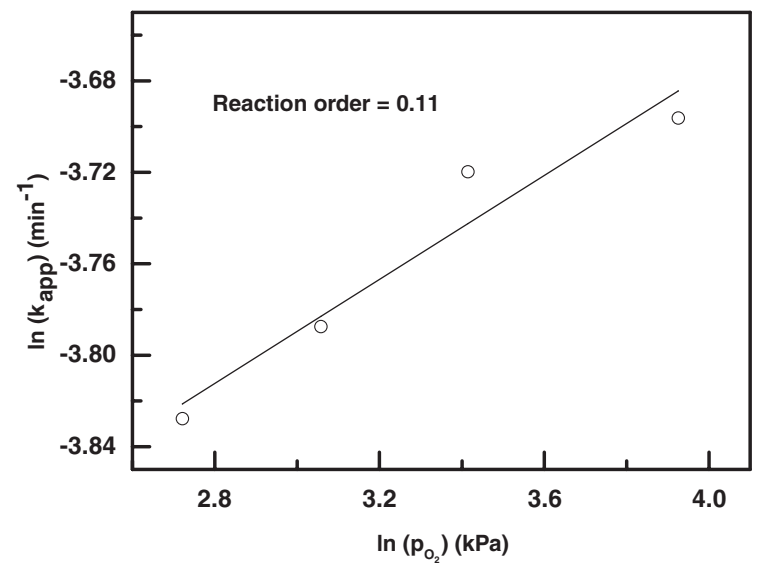

Fig. 8 Dependence on oxygen partial pressure of the reaction rate constant calculated from the results of Fig. 5.

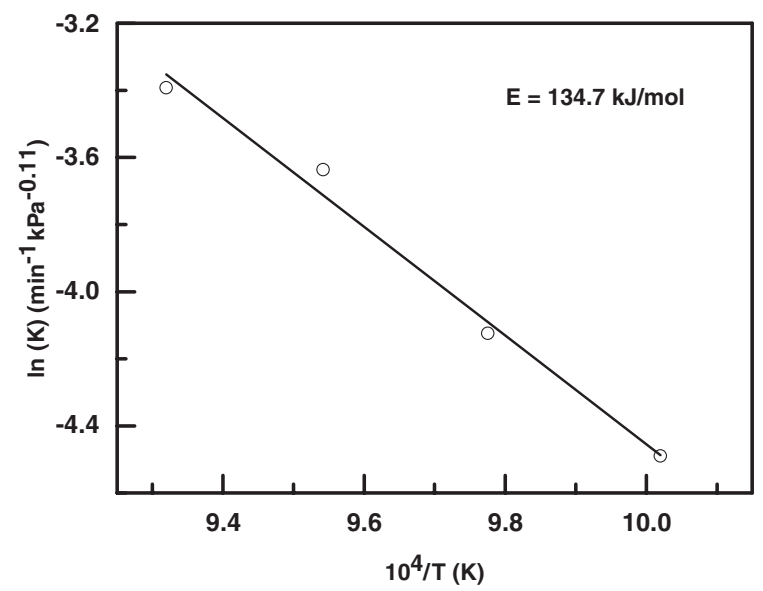

Fig. 9 Arrhenius plot of the rate constants obtained from the results of Fig. 4.

In order to evaluate the oxygen concentrate dependence of $k_{\text {app }}$, the values of $k_{\text {app }}$ thus obtained in Fig. 6 are plotted in Fig. 8 as $\ln k_{\text {app }}$ against $\ln p_{\mathrm{O}_{2}}$. A straight line is obtained. As shown in Fig. 8, the reaction order with respect to oxygen partial pressure is 0.11 . Thus, eq. (3) can be rewritten as

$$
k_{\text {app }}=k f\left(p_{\mathrm{O}_{2}}\right)=k p_{\mathrm{O}_{2}}{ }^{0.11}\left(\mathrm{mim}^{-1}\right)
$$

Also, in order to examine the reaction temperature dependence of $k$, the values of $k_{\text {app }}$ were first calculated from the slopes of Fig. 7. And then, the intrinsic rate constants, $k$, at different temperature were calculated using the values of $k_{\text {app }}$ and eq. (4). Figure 9 is an Arrhenius plot of the intrinsic rate constants. The slope of the straight line placed through the experimental points corresponds to an activation energy of $134.7 \mathrm{~kJ} / \mathrm{mol}(32.3 \mathrm{kcal} / \mathrm{mol})$, which is quite different to that obtained under nonisothermal condition. ${ }^{3}$ This is the reason why in the nonisothermal condition, large amount of sulfate compounds such as $\mathrm{ZnSO}_{4}, \mathrm{CuSO}_{4}$ and $\mathrm{PbSO}_{4}$ during the oxidation reaction is produced before the removal reaction of sulfur happens, ${ }^{3)}$ while in the isothermal condition relatively small amount of them was done during the initial period of the oxidation reaction as shown in Fig. 2. On the other hand, it was found that the oxidation reaction follows well the shrinking-core model, which was different from the reaction mechanism investigated in the nonisothermal condition. In the nonisothermal condition, the reaction mechanism was found to be nucleation and growth model, as explained in the previous paper. ${ }^{3)}$ The nucleation and growth model generally involves the nucleation step at the initial period of whole reaction. However, in the present study the rate data obtained after the initial period of the oxidation reaction of the natural complex copper concentrate with oxygen were only analyzed, as explained previously. It was thus considered that the reaction mechanism investigated in the isothermal condition is different from that done in the nonisothermal condition.

The high activation energy indirectly indicates that the oxidation reaction of complex copper concentrate with oxygen is controlled by chemical reaction. The line through these data can be expressed by the following equation:

$$
k=1.26 \times 10^{5} \cdot \exp \left[\frac{-16,203.1}{T}\right]\left(\mathrm{min}^{-1} \cdot \mathrm{kPa}^{-0.11}\right)
$$

for the oxidation reaction of oxygen with complex copper concentrate of a particle size of $-74 \mu \mathrm{m}$. Using eqs. (2), (4), and (5), the rate of the oxidation reaction of complex copper concentrate with oxygen is represented by the following equation:

$$
1-(1-X)^{1 / 3}=k_{\mathrm{app}} t
$$

with $k_{\text {app }}=1.26 \times 10^{5} \exp \left[\frac{-16,203.1}{T}\right] \times p_{\mathrm{O}_{2}}{ }^{0.11}\left(\min ^{-1}\right)$.

\section{Conclusion}

The oxidation reaction of complex copper concentrate with oxygen was investigated using TGA technique. The reaction temperature was varied between 998 and $1073 \mathrm{~K}$, while oxygen partial pressures of $15.20 \mathrm{kPa}-50.66 \mathrm{kPa}$ were used. The shrinking-core model for a chemical reaction control was found to be useful in describing the kinetics of the reaction over the entire temperature range. The reaction has an activation energy of $134.7 \mathrm{~kJ} / \mathrm{mol}(32.3 \mathrm{kcal} / \mathrm{mol})$ and the reaction order with respect to oxygen concentration in a gaseous mixture with nitrogen is 0.11 . The rate of the oxidation reaction of complex copper concentrate with oxygen is represented by the following equation:

$$
1-(1-X)^{1 / 3}=k_{\text {app }} t
$$

with $k_{\text {app }}=1.26 \times 10^{5} \exp \left[\frac{-16,203.1}{T}\right] \times p_{\mathrm{O}_{2}}{ }^{0.11}\left(\mathrm{~min}^{-1}\right)$.

\section{REFERENCES}

1) R. T. Jones: Conroast: DC ARC smelting of dead-roasted sulphide concentrates, Sulfide Smelting 2002, ed., by R. L. Stephens, H. Y. Sohn (Seattle, Washington, U.S.A, 2002) pp. 435-456.

2) C. HagelUken: Erzmetall 59 (2006) 152-161.

3) B. S. Kim, E. Y. Kim, C. K. Kim, H. I. Lee and J. S. Sohn: Mater. Trans. 49 (2008) 1192-1198.

4) I. Mihajlovic, N. Strbac, Z. Zivkovic, R. Kovacevic and M. Stehernik: Minerals Engineering 20 (2007) 26-33.

5) J. Szekely, J. W. Evans and H. Y. Sohn: Gas-solid reactions, (Academic press Inc., 1976) pp 65-117.

6) H. Y. Sohn and M. E. Wadsworth: Rate Process of Extractive Metallurgy, (Plenum Press Inc., 1979) pp 8-27.

7) H. Y. Sohn: Metall. Trans. B 9B (1978) 89-96. 